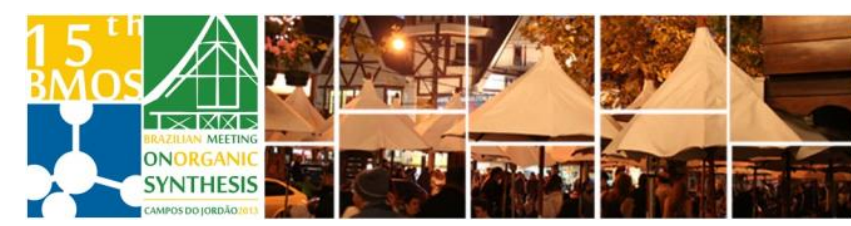

\title{
Further studies on the desymmetrization of cyclic olefins through the Heck-Matsuda arylation
}

\section{Ricardo Almir Angnes, Caio Costa Oliveira, Cristiane Storck Schwalm, Carlos Roque Duarte Correia*}

Instituto de Química, Universidade Estadual de Campinas, UNICAMP, C.P. 6154, CEP. 13084-971,

Campinas, São Paulo, Brazil (www.correia-group.com)

*e-mail corresponding author. roque@iqm.unicamp.br

Keywords: Enantioselective, Heck-Matsuda, Palladium

\section{INTRODUCTION}

The Matsuda variant of the Heck reaction makes use of arenediazonium salts as arylating partners, which directs the course of the reaction to the so called cationic pathway, claimed to be more reactive and selective. This protocol does not require anhydrous conditions or special atmosphere.

The first enantioselective version of this reaction was developed by our group in 2012. Yet many aspects of this reaction remain elusive. ${ }^{2}$ This study has as its main objectives the application of new chiral ligands to the catalytic process.

\section{RESULTS AND DISCUSSION}

The ligands were synthesized through well established methods ${ }^{3,4}$ and were evaluated using the reported ${ }^{2}$ conditions established for HeckMatsuda reaction:

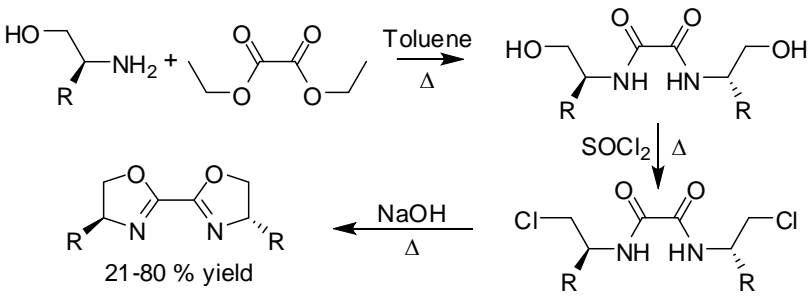

Scheme 1. Synthesis of chiral bisoxazoline ligands

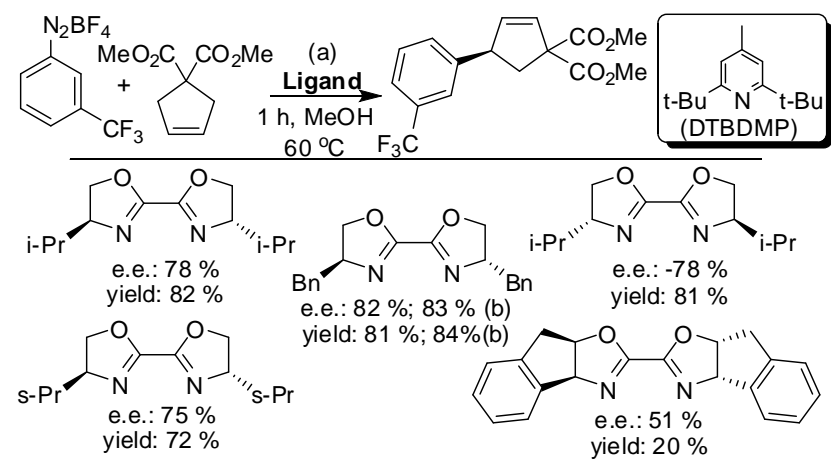

Scheme 2. Evaluation of ligands; (a): 1 eq. DTBDMP, 2 eq. diazonium salt, $10 \mathrm{~mol} \% \operatorname{Pd}(\mathrm{TFA})_{2}, 20 \mathrm{~mol} \%$ Ligand.;

(b) Literature yields in parenthesis.
In addition, the absolute structure were was determined through $\mathrm{x}$-ray crystallogram of the 4nitroaryl product (Figure 1)

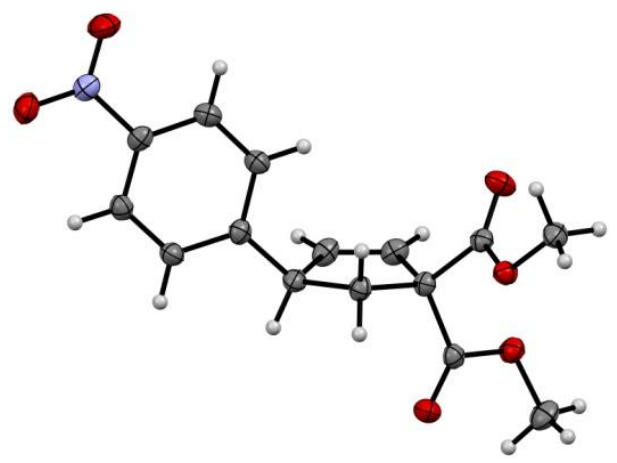

Figure 1. ORTEP diagram of 4-nitroaryl product (Ellipsoids drawn at $50 \%$ probability level)

\section{CONCLUSION}

The chiral bisoxazolines were successfully used as ligands in the enantioselective Heck-Matsuda. The absolute stereochemistry of the adducts are also disclosed.

\section{ACKNOWLEDGEMENTS}

We thank CAPES, FAPESP and CNPQ for financial support.

\section{REFERENCES}

${ }^{1}$ Taylor, J. G.; Moro, A. V.; Correia, C. R. D. J. Org. Chem. 2011, 1403.

2 Correia, C. R. D.; Oliveira, C. C.; Salles Jr, A. G.; Santos, E. A. F. Tetrahedron Lett. 2012, 53, 3325.

${ }^{3}$ Müller, D.; Umbricht, G.; Weber, B.; Pfaltz, A. Helv. Chem. Acta 1991, 74, 232

${ }^{4}$ Levy, J.-N.; Latham, C. M.; Roisin, L.; Kandziora, N.; Fruscia, P. D.; White, A. J. P.; Woodward, S.; Fuchter, M. J. Org. Biomol. Chem. 2012, 10 512 